Elliot, D. L. and Kobayashi, S. (2019) How can PhD supervisors play a role in bridging academic cultures? Teaching in Higher Education, 24(8), pp. 911929. (doi: 10.1080/13562517.2018.1517305)

There may be differences between this version and the published version. You are advised to consult the publisher's version if you wish to cite from it.

\title{
http://eprints.gla.ac.uk/167697/
}

Deposited on: 27 August 2018

Enlighten - Research publications by members of the University of Glasgow http://eprints.gla.ac.uk 


\section{How can PhD supervisors play a role in bridging academic cultures?}

Dely Lazarte Elliot* and Sofie Kobayashi

School of Education, University of Glasgow, Glasgow, UK; Department of Science Education, University of Copenhagen, Copenhagen, Denmark

*Corresponding author:

School of Education, College of Social Sciences, University of Glasgow, St Andrew's Building, 11 Eldon Street, Glasgow, G3 6NH, Scotland, United Kingdom. Telephone: +44 (0)141 330 2467. Email: Dely.Elliot@glasgow.ac.uk http:/www.gla.ac.uk/schools/education/staff/delyelliot/

ORCID ID: https://orcid.org/0000-0003-0711-5719

Dely Lazarte Elliot is a Senior Lecturer in the School of Education, College of Social Sciences, University of Glasgow. After obtaining an MSc in Counselling Psychology and a PhD in the area of Educational Psychology within the higher education context, Dely has become particularly interested in the cross-cultural facets of international postgraduate student experience playing a crucial role in both their academic performance and psychological wellbeing.

Sofie Kobayashi is an Assistant Professor at the Department of Science Education at the University of Copenhagen. She holds an MSc in life sciences and a PhD in higher science education. She has a special interest in teaching and research in the field of doctoral education and supervision, as well as development of and research into documentation and assessment of teaching competencies. 


\title{
How can PhD supervisors play a role in bridging academic cultures?
}

Dely Lazarte Elliot and Sofie Kobayashi

\begin{abstract}
$\mathrm{PhD}$ supervision is generally deemed a rewarding experience as supervisors and students embark on an academic journey together. Pursuing a $\mathrm{PhD}$ in a 'foreign' context inevitably brings forth distinct opportunities and challenges for students and their supervisors. Using Interpretative Phenomenological Analysis, this qualitative study of supervisors and $\mathrm{PhD}$ students examines the cross-cultural facets of doctoral supervision in the light of Urie Bronfenbrenner's bio-ecological theory of human development and its underpinning explanation for supervisory processes and learning orientations. Undertaken in the Danish context, our paper highlights exemplars of contrasting supervisors' and $\mathrm{PhD}$ students' experience in relation to academic and psychosocial adaptations. This research strongly endorses that supervisors' appreciation of the intertwined link between academia and society combined with a positive view of their role in bridging academic cultures can powerfully complement students' adjustments and subsequently make a qualitative difference towards a more fulfilling and meaningful academic journey together.
\end{abstract}

Keywords: PhD or doctoral supervision; international students; academic culture; crosscultural interaction; critical thinking

\section{Introduction}

Given the increase of students pursuing doctoral education in international contexts, this research examines the intercultural exchanges between $\mathrm{PhD}$ supervisors and students using a psychological lens. Considering how academic expectations can play a vital role in a doctoral journey, this paper not only examines the challenges involved but highlights valuable insights from supervisors in facilitating students' adjustments in the new academic environment. Particular attention is given to the quality and impact of intercultural exchanges on informal relationships and on students' academic performance 
and wellbeing (Ives and Rowley 2005; McCormack 2005; Seagram, Gould and Pyke 1998; Wisker 2005).

There is a prevailing view that supervisors regard $\mathrm{PhD}$ supervision as a very rewarding experience - considered 'one of the most enjoyable aspects of many academics' work' (Winchester-Seeto et al. 2014, 610). Perhaps, the task offers an opportunity for embarking on an exciting academic journey with a student in pursuit of a shared interest, while also enabling supervisors to play a vital role in inspiring students' scholarly growth and skill development. Given the strong commitment and great investment required, the complexity that underpins successful PhD study (Bøgelund 2015; Pyhältö et al. 2012) and the reported high attrition rates (approximately 30\% to 50\%) in doctoral education (Church 2009; Gardner 2007; Most 2008; Sakurai, Pyhältö, and Lindblom-Ylänne 2012; Virtanen, Taina, and Pyhältö 2017), each PhD student's completion is a cause for celebration.

Notably, the doctoral student population has become increasingly diverse in recent decades, with a large proportion of students for whom English is not their first language, whether from low-income countries through capacity building programmes, emerging economy countries through home scholarships, or self-funded students seeking a Western education, e.g. AAU (2015); Winchester-Seeto et al. (2014). Against this background, research into the cross-cultural component of $\mathrm{PhD}$ supervision has pointed to the benefits and extra challenges this may bring for the parties concerned (Elliot, Reid, and Baumfield 2016; Robinson-Pant 2009; Winchester-Seeto et al. 2014). With a number of research studies on doctoral experiences focusing primarily on the students' perspectives, there have also been calls for more supervisors' perspectives, e.g. Bøgelund (2015). Notwithstanding that a larger group of people within and outwith academia 
conventionally form a 'constellation of individuals' from which these students can draw resources and support (Baker and Lattuca 2010, 814), we focus on the potential complementarity of social and academic interactions between supervisors and international $\mathrm{PhD}$ students.

\section{Cross-cultural facets of doctoral learning and supervision}

It is a truism that $\mathrm{PhD}$ education undertaken internationally offers an enriching and challenging experience for students emanating from their immersion in different academic and societal contexts. These experiences vary immensely and are regarded either as a distinct entity or overlapping entities within the formal or informal curricula, academic or non-academic practices, and direct or tacit activities (Xu and Grant 2017), where each interaction offers valuable learning potential (Elliot et al. 2016). Likewise, supervisors' interactions with international students could bring challenges but could equally enhance their intercultural competences and serve as a resource for meaning enrichment (Akkerman et al. 2006; Kiley 2003).

Friction stemming from unaligned expectations between supervisors and $\mathrm{PhD}$ students is widely reported, but such issues are arguably more intense in cross-cultural contexts (Holbrook et al. 2014; McCormack 2005; Woolderink et al. 2015). WinchesterSeeto and her colleagues $(2014,610)$ frame these cross-cultural issues as 'intensifiers', i.e. issues that affect the majority of $\mathrm{PhD}$ students are deemed to be more pronounced in cross-cultural contexts, thereby requiring adjustment and transition (see also Fotovatian 2012). The 'intensifiers' identified were 'language, cultural differences in dealing with hierarchy; separation from the familiar; separation from support; other cultural differences; stereotypes; time and what happens when [the student] returns home' 
(Winchester-Seeto et al. 2014, 610). Lovitts (2005) further contends that the transition from Master's to $\mathrm{PhD}$ is already challenging, and more so when students simultaneously make the shift into the unknown territory of a different academic and societal culture, thereby producing multiple and simultaneous transitions and adjustment at various levels (Jin and Cortazzi 2006; Jindal-Snape and Rienties 2016). This can lead to students struggling and striving to adapt, negotiate and broaden their horizons to succeed, often in a setting that takes the privileged position of the Western model for granted (Barron and Zeegers 2006; Kidman, Manathunga, and Cornforth 2017).

Bronfenbrenner's (2005) comprehensive Bio-ecological Systems Theory of Human Development is considered pertinent to this discussion. Accordingly, the nested ecological system explicates the interlinked influences and opportunities for growth and development via the individual's interaction within the microsystem (family, school), mesosystem (linkage among the microsystem constituents), exosystem (community, parents' workplace) and macrosystem (culture, customs, traditions, norms and practices) - further connected through the chronosystem (life milestones). This theory elucidates how learning gradually develops via the person's unique and coalesced interaction within each of the systems and actively contributes to his/her continuing development. In extending Bronfenbrenner's theory, it is worth noting that a beautifully complex coexistence of two ecological systems develops once international students move away from their original (home country) ecological system to pursue an education in a new (host country) ecological system. Reciprocally interacting elements from various systems that affect personal, social and learning practices in particular are arguably crucial for these educational sojourners as they can lead to valuable learning opportunities as well as 
potential conflicts arising from competing influences emanating from the original and the new ecological systems (Elliot, Reid, and Baumfield 2016).

In this connection, there are studies to support how cultural practices can create distinct conceptualisations of what is regarded as effective learning and effective learning strategies as well as how cultures inform learners' ways of thinking. Li's (2005) 'mindvirtue' orientation framework serves as an exemplar. Whereas the mind orientation model stresses the key importance of thinking, where 'inquiry guides the learner to question the known and to explore and discover the new', the virtue orientation preference is on moral and social perfection, 'mastery of the material' and societal contribution (191). The contrast between the mind and virtue orientation models does highlight the tacit but powerful impact of learners' beliefs on learning - beliefs that subsequently manifest themselves in students' learning behaviour (e.g. reluctance to criticise or question authority). Arguably, international students' learning expectations are often strongly influenced by their societally-informed holistic understanding of learning pedagogies they have experienced and previously considered as the norm. Such expectations encompass distinctive educational practices, e.g. forms of address, approaches to teaching, assessment and attendance (Carroll 2015, 25-26). Western practice implies a move away from a hierarchical relationship into a higher degree of equity and this conveys a different expectation. Such implicit, but mismatched expectations can lead to situations where students implicitly await leadership from supervisors while supervisors trust and expect students to take the initiative (Carroll 2015; Winchester-Seeto et al. 2014). If left unaddressed, such mismatched expectations lead to challenges that might be difficult to overcome later on. Hence, a healthy understanding of academic acculturation and 
transition to a new culture is crucial, whether in academic or non-academic spheres, and in formal as well as informal contexts (Elliot, Reid, and Baumfield 2016).

Despite recent developments and moves towards 'mentoring' and 'socialising into disciplinary communities and discourses' (Manathunga and Goozée 2007, 309-310), there remain traces of the previously dominant traditional master/apprentice model influencing the asymmetrical relationship between the $\mathrm{PhD}$ supervisor and the student (Kobayashi 2014). Since 'supervision is inherently a social activity' and interactions with supervisors play a vital role in doctoral students' development as researchers (Amundsen and McAlpine 2009, 332), a scrutiny of the supervisory relationship remains pertinent. With the parallel between supervision and teaching practices, we then consider 'international classroom' issues in examining the cross-cultural facets of doctoral learning and supervision (Choy, Li, and Singh 2015). According to Carroll $(2015,32)$, misunderstandings in the classroom can occur with: a) relations between teachers and students; b) teaching methods; c) assessment; d) academic writing; and e) academic/critical reading. Lee, Farruggia, and Brown (2013) concur that relationships, methods of learning and teaching, academic writing, critical reading, language limitations, academic content and learning styles are key to the $\mathrm{PhD}$ supervision process.

\section{Denmark as host country}

The qualitative nature of this study calls for a thorough description of the context to enable readers to judge transferability to their own context. This study was undertaken in Denmark, and as a host country Denmark can be considered extreme based on Hofstede's cultural dimensions (Hofstede, 1984). Furthermore, teaching and learning, and hence 
supervision is strongly influenced by the Nordic/German 'didaktik' educational tradition (Hopmann 2007).

\section{Cultural dimensions}

Although Hofstede's cultural dimensions are disputed, since cultures within academia vary from the corporate cultures that Hofstede's dimensions are derived from (Signorini, Wiesemes, and Murphy 2009), this theory equally offers some insight into Danish culture. Figure 1 indicates comparison of power distance, masculinity and uncertainty avoidance in selected countries, as defined below (see geert-hofstede.com/national-culture.html):

Power Distance - 'the degree to which the less powerful members of a society accept and expect that power is distributed unequally'

Masculinity - 'a preference in society for achievement, heroism, assertiveness and material rewards for success'; femininity - 'a preference for cooperation, modesty, caring for the weak and quality of life'

Uncertainty Avoidance - 'the degree to which the members of a society feel uncomfortable with uncertainty and ambiguity'

[To insert Figure 1 here]

Figure 1 denotes the difficulty in decoding cultural expectations with respect to hierarchy and interaction norms in Denmark because of low power distance combined with low uncertainty avoidance. Rules are few while self-regulatory codes prevail, albeit often tacit and invisible. Disagreement is welcome, i.e. it is acceptable for subordinates to question or disagree with their superiors. Leaders trust their teams and delegate responsibilities 
and in turn, a high degree of autonomy is required of employees. Dr and Professor are not used when addressing superiors; instead, respect is earned by proving one's expertise. The low score on the masculinity scale pertains to a culture of lengthy discussion until consensus is reached. The tolerance for ambiguity is also reflected in the loose structures and informal working environment in Danish universities. Finally, significant importance is paid to sound work-life balance, another aspect of the feminine society (low masculine society) (Ekelund 2010).

\section{Didaktik and bildung tradition in Danish education}

As stated earlier, Danish educational systems have their roots in the German didaktik tradition as opposed to the Anglo-American curriculum tradition (Hopmann and Riquarts 2000). Didaktik is regarded as a tradition of thinking about teaching and learning, where the concept of bildung (formation) is central. A brief definition of didaktik and bildung does not exist, but Hopmann (2007) provides comprehensive descriptions. In the didaktik tradition, the ability to know or to do something is not the goal of teaching and learning per se; rather, knowledge and skills are considered transformative tools for unfolding the learner's unique self. It may not be possible to capture bildung in one English term, as it broadly encompasses combined notions of formation, education, experience and erudition. The didaktik tradition differentiates between the content and its educative meaning. To illustrate, when learning about the Great War, didaktik is likely to ask 'What can we learn about mankind by understanding the Great War?' rather than simply learning about the history of the Great War (Hopmann 2007, 116). Teachers are given the autonomy and professional competence to adjust the subject matter and the assessment with a view to 
supporting pupils in constructing their own understanding, as represented in the didaktik triangle (see Figure 2).

[To insert Figure 2 here]

Nordic education, from primary school onwards, rests on the belief that individuals can develop, and that society influences the development of the individual. This implies an internalised resistance against summative assessment of performance where Danish assessment culture tends to strive towards mastery goal orientation for the individual to develop and become a whole person (Midgley, Kaplan, and Middleton 2001), which is different from the curriculum-driven tradition and performance goal orientation practised in Anglo-American educational systems (Dolin 2016). In the Danish PhD context, supervisors tend to have greater trust in doctoral students as self-regulated learners with a mastery goal orientation. As a result, supervisors have high expectations from doctoral students in terms of autonomy and equity from the outset while resisting judgement of student performance or the doctoral student as a person (Kobayashi 2014). Traditionally, $\mathrm{PhD}$ students are employed at the university while undertaking studies under that university's $\mathrm{PhD}$ school, and as such are regarded as colleagues and members of staff even now, when increasing numbers are funded via scholarships from the $\mathrm{PhD}$ students' home countries (Kobayashi 2014; Kolmos, Kofoed, and Du 2008). As employees, PhD students are expected formally to report to the head of department. The principal supervisor holds formal power often only as signatory of documents for approval by the graduate school or recommending termination if the $\mathrm{PhD}$ student does not meet the expected requirements. 
It is worth noting that research into cross-cultural supervision is very limited in the Danish context. Bøgelund's studies are an exception (Bøgelund 2013; 2015; Bøgelund and de Graaff 2015), but the focus of her research is on the adaptation to the new agendas of universities with higher demands on productivity and efficiency. The study by Kolmos, Kofoed and Du (2008) was mainly concerned with industrial PhDs. Maksimovic and Kobayashi (2018) investigated international PhD students' experiences in Denmark, with a focus on the use of the quest metaphor. The doctoral thesis by (Kobayashi, 2014) has some discussion of cross-cultural supervision in a Danish context, but not an in-depth empirical study on cross-cultural supervision.

Following our review of doctoral education, the dearth of research within the context of the increasing numbers of international $\mathrm{PhD}$ students and discussion of distinct challenges in cross-cultural supervision, we would argue that there is warrant for undertaking an exploration in the Danish context as a specific example of the phenomenon of cross-cultural supervision. In the light of Hofstede's cultural dimensions and the educational foundation in the Nordic/German 'didaktik' tradition, the Danish context provides an example of more extreme cultural differences that would arguably make it more difficult for supervisors and $\mathrm{PhD}$ students to bridge the gap (see Figure 1). Hence, if we find that supervisors have strategies that seem to work in bridging the gap, then results could be transferable to less extreme contexts (meaning most other host countries). Since we are investigating useful strategies employed in a less favourable context, it is meaningful to interview experienced supervisors who are interculturally proficient. 
Therefore, this phenomenological study is expected to elucidate more nuances of the complex ways that the co-existence of two ecological systems could play out in the supervisory processes. Specifically, we endeavoured to address the following questions: 1) How do supervisors and $\mathrm{PhD}$ students' perspectives compare in terms of the conventions and practices characterising Danish PhD supervision?

2) What strategies do experienced and interculturally-proficient supervisors employ to bridge academic cultures in the Danish context?

\section{Methodology}

This study employed a small-scale conventional interview method with international $\mathrm{PhD}$ students and experienced supervisors who are highly competent in intercultural communication. The study was undertaken in the science faculty of a Danish university, and based on the 2016 figures, there were around 1,160 PhD students in the Science Faculty, comprising 46\% female, 54\% male; 45\% Danes, 25\% from other European countries, and 30\% from outside Europe. Average age at enrolment was 28, and 85\% commenced PhD studies following a Master's qualification. A PhD is limited to three years of combined work and study, entailing six months of coursework and a maximum of six months of teaching. The average completion time is 3.3 years enjoying a completion rate of around $88 \%$. Most $\mathrm{PhD}$ programmes $(90 \%$ in 2016$)$ are partly or fully funded by external bodies (PhD-School 2016). Contrary to the convention whereby doctoral students select their supervisors (Ives and Rowley 2005), externally-funded $\mathrm{PhD}$ positions in Denmark are advertised internationally and the supervisor employs the most suitable student for the job/study. International $\mathrm{PhD}$ students who are in receipt of a scholarship from their home country are an exception, as they are not formally employed. 
Nevertheless, it is worth noting that the general perception of $\mathrm{PhD}$ students as colleagues prevails across domestic and international groups.

\section{Participants}

Interview participants were six international $\mathrm{PhD}$ students and six experienced supervisors from Life Sciences. They were recruited through the second author's networks. Criteria for recruiting supervisors included: a) having supervised at least two international $\mathrm{PhD}$ students to successful completion; and b) international collaboration experience in teaching and/or research. This is to ensure ample supervision experience and a good level of intercultural competence. PhD students were recruited using a snowballing process, starting with doctoral students who completed a course with the second author. No specific recruitment criterion except variation in students' country of origin was employed. It is worth noting that participating students were all university employees, which meant that they applied and were subsequently selected by the supervisors as the most suitable candidates for the posts. Two students completed their MSc in Denmark; the rest embarked on their PhD after completing an MSc elsewhere. One was in a double $\mathrm{PhD}$ programme shared between two European universities. Students ranged between six months and almost three years into the programme at the time of interview. Table 1 presents some demographic information about the two groups of participants.

[To insert Table 1 here]

\section{Procedures}


With the research's phenomenological focus, the interviews followed an interview guide in a semi-structured format, which allowed exploration of themes that were meaningful to the respondents (Smith and Osborne 2008). Data were collected in spring 2013, with the help of the research assistant who holds an MA in international negotiations and is proficient in intercultural communication. Interviews were audio-recorded and transcribed verbatim. The inductive interview analysis conformed to the rigorous steps of Interpretative Phenomenological Analysis (IPA) developed by Smith and Osborne (2008, 75), i.e. a) line-by-line annotation in search of preliminary themes per case, b) transforming themes into concise phrases that capture its quality, and c) clustering the themes to produce the master list of superordinate (main) and subordinate (minor) themes. This hierarchy of themes was then reiteratively employed for all transcripts with a view to finding either 'idiosyncrasies' or 'convergences'. The same procedure was applied to both supervisor and $\mathrm{PhD}$ student interviews, albeit independently. The IPA approach enabled us to get close to the participants' lifeworlds with a view to representing and interpreting them. Since the interviews with supervisors were conducted in Danish, preliminary analysis was undertaken by the second author who is proficient in both Danish and English - a limitation on the part of the first author. Excerpts were translated into English from which the first author analysed the selected data to apply some limited cross-checking, followed by comprehensive discussion with the first author to confirm legitimacy with the emergent idiosyncratic and converging themes. As part of the 'double hermeneutics' involved in IPA, a two-stage interpretation process meant that the research not only endeavoured to examine the participants' world but also represent this world through the researchers' perspective. Following Yardley's (2008) advice, demonstrating the soundness and rigour as well as transparency involved in the research process is an 
effective way by which researchers can argue that their qualitative findings are valuable and trustworthy - something that was seriously considered in every aspect of this study.

\section{Results}

With its focus on seeking the perspectives of both international $\mathrm{PhD}$ students and supervisors concerning cross-cultural supervision in the Danish context, this paper reports the important facets, i.e. contrasting perceptions generated in the first three themes 'differing approaches to learning', 'mismatched expectations on feedback-giving', and 'development of critical thinking'. These themes subsequently led to the necessity for bridging academic cultures in the fourth theme.

\section{Differing approaches to learning}

It has been observed that in cross-cultural supervision, students' and supervisors' practices could be associated with one of two learning dichotomies, one that is geared towards self-regulated learning or another that is heavily directive by nature. As exemplified by the remarks made by two students and a supervisor in this study, differing practices could potentially lead to tensions. Wang expressed unfamiliarity, lack of understanding and even annoyance concerning the 'interactive' discussion that conventionally characterises the Danish educational setting. His remarks on discussions being 'a waste of time' convey the perceived 'foreignness' of the idea behind interactive learning.

...it's more interactive between the students and the teachers [here].... Sometimes

I get a little bit annoyed [when] one student just keeps asking questions..... And 
mostly, the teacher will not stop it. ... You can easily find it in the references, or you can just think about it ... [it's] a waste of time. (Wang, PhD student).

Additionally, the passages below demonstrate a contrast of learning expectations.

Whereas Reza expected to learn from and through the supervisor, the supervisor raised the importance of students realising that their research project is their responsibility, and that entails confidently taking ownership of it.

[Being independent] was very difficult for me in the beginning... what if I'm making a mistake, what if [my supervisor] says: 'What did you do?' ... he is actually open-minded ... and ... not interfering with my decisions. But sometimes I need to have a discussion ... a proper lab meeting. I [may] have the most stupid questions but I'm not a professor, I'm not God ... I'm here to learn. (Reza, PhD student)

[I] throw a lot of ideas ... then they have to ... decide which they want to follow ... one of the big challenges is to make them take responsibility ... that it is their project, and [not] just do as I say. ... the problem arises when they are afraid of taking decisions by themselves, and they feel a need to get all decisions validated to the smallest detail. (Janne, supervisor)

As shown by Reza (PhD student) and Janne (supervisor), unforeseen pressure can stem from unfamiliarity or indifference to a 'foreign' mode of learning leading to contrasting expectations between students and supervisors. A combination of 'very rigid hierarchies' characterising supervision structures back home and students' openness to the generous academic freedom in the Danish context could easily be a daunting experience, as Reza found. While appreciating the Danish academic tradition of autonomy and equity, students also recognise that this entails 'more self-discipline' (Zuki, PhD student). It is 
worth noting though that the orientation for self-regulated learning is not solely linked to the didaktik tradition. Zuki explains that the level of independence expected from students is partially strengthened by the 'half-way employee' nature of the Danish $\mathrm{PhD}$.

\section{Mismatched expectations on feedback processes}

Since cross-cultural supervision arguably involves a natural meeting of cultural practices, they also contribute to oddness, puzzlement, even mismatched expectations between international students and supervisors, e.g. in assessing students' performance.

...I don't understand if they are happy with me, or angry because they never show that... you can't see something on his face... everyone is always very helpful and laughing all the time... so I don't understand. It's a challenge. (Susheila, PhD student)

International $\mathrm{PhD}$ students' accounts hint at a craving for judgement or assessment of their performance that they do not get from Danish supervisors. Although supervisors are regarded as 'so nice' who 'never say you are bad' (Wang, PhD student), such a perception could also build 'some [invisible] walls'. At times, this leaves students wondering 'what supervisors are actually thinking and how they evaluate' students' performance (Zuki, PhD student).

In comparison, Anton (supervisor) acknowledges the need to recognise complexity when assessing students due to their different backgrounds. He dismissed the idea of judging students using norm-based assessment. Instead, he asserted that good feedback-giving must focus on the task and learners' mastery. 
[As for] rating [international students] ... you are comparing apples and pears, you cannot compare all PhD students - they come from different backgrounds ... I have a rather direct [way of telling] people in a relaxed manner: 'These are some really stupid mistakes you've made, you didn't think it over properly...' ... some people think that I am very direct and no-nonsense ... I do it ... not from above, but [to show equal level of relationship]. (Anton, supervisor)

Like Anton, supervisors with a Danish cultural heritage tend to trust students' ability to develop by giving them task-orientated feedback, alluding to a mastery goal orientation. The sense of insecurity from the voice of international students possibly arises outwith the learning traditions of their country of origin, perhaps with greater emphasis given to performance goals rather than the mastery goals that are firmly embedded in the Danish didaktik educational system (Midgley, Kaplan, and Middleton 2001).

\section{Development of critical thinking}

Critical thinking is at the core of PhD research education (Brodin 2014), and in this study in the context of Life Sciences, the notion of critical thinking also broadly encompasses scientific ways of thinking. While discussions are centred on the cultural influences on learning, they also powerfully illuminate the levels of influences on the development of students' critical literacy. This accords with the several rival strands associated with the concept of critical thinking: philosophical, educational and socially active perspectives (Davies and Barnett 2015). While the philosophical perspective often aims to help with the clarity and rigour in one's thinking, the educational perspective concerns students' developing a critical attitude to benefit the wider society, and the socially active perspective refers to the transformation of critical attitudes among students. Davies and Barnett assert how these three perspectives are intertwined and 'are by no means entirely 
separable' (6) - a view that we strongly support. Starting with the pedagogical orientation previously received, this affects students' conceptualisation of 'learning':

...they gave me a book, 200 pages, and I asked, 'Professor, do you want me to memorise 200 pages?' and he looked me and said, 'Are you crazy, [nobody is asking you to memorise 200 pages]? You just use it to develop this project.' ... That's exactly the difference, and ... that is critical. [We] international students ... just stack everything inside [ourselves]. (Reza, PhD student)

The influence of previous learning orientations seems to have been strongly embedded in students' psyche and can be observed in the way international students approach academic reading, for example, which greatly contrasts with how Danish supervisors read academic papers.

...it's two sides of the same coin. When I read a paper ... I read with the assumption that it's a lie ... I am looking for weaknesses in their methods and so forth. So, even my very best [South East Asian] student, he reads a paper and then he says: 'They found this and that.' and then I say: 'No, they didn't, they found something that indicates it, but they didn't actually find it.' (Asger, supervisor)

Henning (supervisor) further explained that these students tended to be exposed to an educational system, which emphasised knowledge reproduction rather than learning through discussion, which includes developing skills to think critically. This manifests itself in the reported contrasting approach to reading a paper where a clear distinction was made between a questioning and an accepting attitude. Arguably, apart from these pedagogical variations, various influences at the societal and personal levels are proportionately influential and can reinforce or weaken one's ability to think critically (Davies and Barnett 2015) - supporting the notion that 'pedagogy is not necessarily 
culturally neutral' (Manalo et al. 2015, 323). These are exemplified in three supervisors' observations:

...some of that independent thinking actually might be present, but it's weakened because they believe in authorities ... [it is] one thing ... to think independently, but it's something else to voice it. (Janne, supervisor)

...it's very seldom that the international, [particularly] Asian students will ever [contradict authorities], they can have strong opinions but they will align. And some will be extremely humble. (Henning, supervisor)

[As for] the African universities where I have seen how it's going ... that is definitely not encouraging critical thinking [but] the $\mathrm{PhD}$ students I have met, from Kenya and Tanzania ... I feel that at a personal level, they were critical thinkers. (Jeppe, supervisor)

Hofstede's (1984) notion of power distance, which tends to affect some societies more than others, could possibly explain students' hesitancy to 'voice' an alternative view (see Figure 1). As per Henning's and Janne's observations, either the societal culture does not openly encourage it, possibly due to hierarchical-related respect towards people of authority, or that critical views of a contentious nature (political, royal) tend to be stifled. By contrast, Jeppe (supervisor) asserted that expression of critical thinking can also be observed at 'a personal level'. Despite not being supported by the educational system, students can have the propensity to develop critical thinking, subsequently becoming part of their personal disposition (Davies and Barnett 2015).

\section{Bridging academic cultures}


Supervisors are arguably key players in facilitating students' acculturation into the academic discipline - an important first step towards meeting the requisite standards and achieving a $\mathrm{PhD}$. In this section, we will report instances of how Danish supervisors act as mediators of the new academic culture for these students. Supervisors articulated the need for students to become self-regulated learners by taking 'responsibility for their project' from the beginning (Janne, Anton and Asger). Supervisors' responses indicate that they actively used their understanding of students' adaptation in their approach, e.g. students not being comfortable with flexible learning pedagogies.

... it is important to have ... procedures because they are more used to formal ways ... they are used to 'Now, we do this from A to B.' and if it is ... too loose in the beginning, they are not comfortable with that... it is better that they take the decision, but at other times, it is okay to say: 'You know, now you will do like this.' (Anton, supervisor).

Gradually, supervisors then introduce the value of $\mathrm{PhD}$ students taking ownership and establishing a more symmetrical relationship with students. Janne expressed this as: 'My ideal is the culture without leadership, where we are all equal ... and that should be the tone we use in communication ... the tone ... I increasingly build with foreign $\mathrm{PhD}$ students'. In conveying the importance of equity, supervisors also linked it to forging a healthy relationship with them. As PhD students' first port of call, it can be expected that supervisors' remit also constitutes helping make students' 'feel safe' and that they are 'being [part of] a family', or in general terms, providing forms of 'pastoral care' (Wang and John, PhD students; Viola and Henning, supervisors). 
...it requires more time, it's not enough with a meeting every four weeks. It's the daily contact, which is important, then you get close. They are used to contact, and then they open up. (Henning, supervisor)

If you, from the start, have this directness and informality and invite them home for dinner, which I often do, and 'Let's go to the park and grill and walk about with the bare-footed professor.' ... everyone likes that ... that also means [breaking the] barrier.... (Anton, supervisor)

Additionally, 'humour' is another personal strategy to convey honesty and a 'friend-like' attitude (Asger, supervisor) while taking caution that it is not the type of friendship that could damage their professional working relationship. Notably, supervisors' actions are gestures of goodwill prompted by a yearning to assist students' academic progress and well-being. They acknowledge that a $\mathrm{PhD}$ is not only an academic endeavour, after all. It also entails 'undergo[ing] a personal transformation process' (Asger, supervisor).

Moreover, the effort to pursue equity in the relationship is aligned with the Danish resistance to autoritetstro, translated as 'respect for authorities'. Asger (supervisor) was 'very aware' of this academic (and societal difference), and therefore, of the necessity 'to break that respect for authority'. As Reza (PhD student) exclaimed: 'when I came to Denmark, I used to call my professors and everybody by 'Doctor' ... 'Dr Professor' and then, I realised that this is not acceptable in this country!' This then leads to supervisors encouraging international $\mathrm{PhD}$ students to agree as well as contradict and oppose their supervisors, as a crucial component of intellectual growth. Janne (supervisor) explained that students' reluctance to 'contradict' becomes even more evident when compared to Danes who have no reservations in saying 'I don't get that.' if they find themselves in similar circumstances. 
Sometimes, I said: 'Something needed to be changed,' and the student answers 'Yes', but she doesn't change it. Then, I followed up and asked her why ... there is actually a reason why, but this is not voiced beforehand. (Janne, supervisor)

They will not directly contradict me, but they will also not change their manuscript, and then, it starts circulating between us endlessly.... (Henning, supervisor)

Possible reluctance to contradict the supervisor is explained by Reza ( $\mathrm{PhD}$ student): 'Because in my country, it is not just about the grades or number of publications, it's also about your attitudes'. Beyond the notion of respect, having the right attitude is almost a requirement for those who aspire to join the academic community: 'You have to be like them, otherwise, you are not welcome,' arguably a manifestation of the powerful influence of the student's original ecological system (Bronfenbrenner 2005). Traces of hierarchical influence back home also typically lead to students' confrontation-avoidance with the supervisor, while disregarding the advice received. Viola (supervisor) notes that it sometimes 'takes a long time to find out' that students were actually in disagreement. She also started employing strategies to urge students to voice their views by saying: ' $\mathrm{I}$ can see that you are sceptical', which proved to be effective, rather than 'I can see that you disagree, shall we discuss this?' Taking the students' perspective is viewed to be more empathetic, especially for students' who are concerned about losing face because of not being able to understand.

If I don't understand, I shouldn't say 'Yes' ... But I have tended to ... say 'Yes' or smile [even when I] really don't [understand and] (laughing) things are not really [clear]. In the end, they can see ... that my face is totally confused. Then he [repeats]: 'Do you really understand or ...?' and then I say 'No.' (Zuki, PhD student) 
These differing perspectives of experiences surrounding supervision demonstrate how students' general lack of societal familiarity can affect their confidence to operate in a new environment (Viola, supervisor). Likewise, supervisors exemplify how they can serve to bridge understanding of societal non-verbal gestures and codes in assisting international students' ability to 'read' others and decode the expectations in the new academic culture. On the outside, these examples merely look like ordinary intercultural exchanges, but they were intentional and sensible approaches in building academic cultures that form a crucial part of international doctoral student transition and a meaningful academic journey together.

\section{Discussion}

In this section, we first aim to offer an analytical interpretation of the generated themes in the light of Bronfenbrenner's Bio-ecological Systems theory. Secondly, we will illustrate with an example (i.e. critical thinking) how the collective influences from the nested systems in the ecological system could permeate the personal, pedagogical and cultural spheres. Based on our findings, we will highlight in the third section pragmatic strategies how $\mathrm{PhD}$ supervisors can capitalise on their position to support students. Finally, we will synthesise these points before offering the main research contributions (and limitations).

As shown in the first three themes: a) differing approaches to learning; $b$ ) mismatched expectations on feedback processes; and c) development of critical thinking, concerns tend to revolve around what $\mathrm{Xu}$ and Grant (2017) regard as 'the enrooted voice of respectful dependence and the alien [voice] of critical thinking' (5) characterising some students. These themes exemplify the competing influences between the original and new ecological systems (Bronfenbrenner 2005). Interestingly, a doctoral educational 
sojourn affords the time and unique space for these forces from two (distinct) ecological systems to meet - simultaneously fashioning reflective learning and adjustment (Elliot, Baumfield, and Reid 2016; Elliot et al. 2016; Elliot, Reid, and Baumfield 2016). Observed contrasting pedagogical orientations influencing learning preferences, expectations for learning and feedback and propensity for critical thinking are arguably key academic areas that necessitate bridging towards achieving a more congruous academic journey.

With a focus on the third example, the value attributed to critical thinking and the process of developing and articulating critical thinking seem to serve as an ideal starting point for appreciating further what underpins differing modes of learning practice and mismatched expectations, for which bridging academic cultures becomes imperative. This is diagrammatically represented in Figure 3.

[To insert Figure 3 here]

Given a specific reference to the development of critical thinking, this model suggests the triarchic ways in which capacity for critical thinking can be acquired, i.e. via: a) one's personal disposition; b) pedagogical orientation received; and c) societal structure and/or political systems that are tacitly embedded in the prevailing culture of the student's original ecological system (Bronfenbrenner 2005). Although there is literature to support various contributory factors to the development of critical thinking (e.g. Andrews 2015; Choy, Li, and Singh 2015; Egege and Kutieleh 2004), our study not only strongly supports such propositions but argues for their strong interconnectedness. 
While some challenges arise from and via the numerous interactions between $\mathrm{PhD}$ students and supervisors, there are highly valuable lessons to be learned particularly from our interculturally-proficient Danish supervisors, where the notion of bildung is strongly embedded and manifests itself in their didaktik educational tradition. First, as far as supervisors are concerned, there is a conscious attempt to pursue equity or a symmetrical relationship, which Dysthe $(2002,519)$ refers to as 'the partnership model'. Their strategic actions are underpinned by the flat organisational structure that they tend to strive towards. Supervisors see pursuit of a symmetrical relationship as a critical first step towards fostering students' independent thinking and self-regulated learning, and ultimately as a precondition for fostering critical thinking. Another approach for pursuing this equity is through reducing students' perceptions of barriers arising from 'power distance'-related expectations, which tend to be more prevalent among students from very hierarchical societies. In Denmark, this is referred to as autoritetstro or 'respect for authorities', which mirrors the 'power distance' element in Hofstede's cultural dimensions (Hofstede 1984) subsequently becoming a barrier that supervisors endeavour to overcome. This leads to the third strategy, which is to address students' difficulty in disagreeing with their supervisors by impressing on them the idea that doing so is not the opposite of pursuing 'harmony' - something possibly influenced by the home culture, particularly by some collectivist principles. Pursuit of harmony may sound very positive but as the findings indicate, hesitancy to openly contradict supervisors could ironically bring forth the opposite result. The actions demonstrated by these Danish supervisors are genuine exemplars of effectively bridging academic as well as psychosocial cultures with 
a view to empowering and supporting international $\mathrm{PhD}$ students' overall coping and successful adaptation to the new doctoral supervision context.

Taken together, what can be learned from this research on the cross-cultural facets of doctoral learning and supervision? As we explained elsewhere, the educational sojourn is a distinct occasion that enables the co-existence of two ecological systems, i.e. the ecological system, which was 'the norm' prior to the sojourn and the new ecological system that the international students become exposed to as they become immersed in both academic and societal cultures of the host country (Elliot et al. 2016; Elliot, Reid, and Baumfield 2016). Depending upon the extent of these differences, the educational sojourn tends to reinforce any similarities and differences that manifest themselves through differing modes of learning practices and mismatched expectations. This then leads to the inherent need to bridge academic (as well as psychosocial) culture - arguably a significant component in cross-cultural doctoral learning and supervision.

It is posited that bridging academic cultures equally applies to supervisors; their intercultural exchanges with international students on academic and non-academic matters are contributory factors to supervisors' thinking development and broadening of perspectives (see Tran, Green, and Nguyen 2017). In these cross-cultural interactions, supervisors specifically highlighted how the experience contributed to their personal and professional growth, e.g. raised awareness on 'how others read you', personal enrichment of cultural knowledge and understanding via exposure to other cultural perspectives, and understanding alternative rationale for other ideas, intentions and behaviours. 
We use Bronfenbrenner's Bio-ecological Systems as a framework to recognise the challenges that international $\mathrm{PhD}$ students experience in their transition to the Danish ecological system and focus on the strategies that interculturally-proficient Danish supervisors apply in promoting successful and meaningful doctoral journeys. Given the inherent challenges specific to Denmark, the lessons gained can potentially be transferred to less extreme contexts. Notably, experienced and interculturally-proficient Danish supervisors acknowledge not only the intertwined nature of bridging academic and societal cultures (arguably linked within Bronfenbrenner's ecological system), but also the pressure that the sojourn subsequently brings. Equally importantly, they recognise that adjustments do not merely depend on international students alone. On the contrary, they are in an ideal position to respond to these adjustments in a supportive capacity and a constructive manner. Notwithstanding the role of doctoral learners', this paper highlights supervisors' 'position of support' as doctoral learners navigate new academic contexts and understand and meet the requisite standards to achieve a doctoral qualification. Along the way, supervisors can simultaneously enable a journey that is more meaningful and fulfilling for both international doctoral learners and supervisors. 


\section{References}

AAU (Association of African Universities). 2015. "Annual Report - Accelerating human development in Africa through higher education." In, 48. Accra, Ghana: Association of African Universities.

Akkerman, Sanne, Wilfried Admiraal, Robert Jan Simons, and Theo Niessen. 2006. "Considering diversity: Multivoicedness in international academic collaboration." Culture \& Psychology 12 (4):461-85.

Amundsen, Cheryl, and Lynn McAlpine. 2009. “ 'Learning supervision': trial by fire." Innovations in Education and Teaching International 46 (3):331-342. doi: 10.1080/14703290903068805.

Andrews, Richard. 2015. "Critical thinking and/or argumentation in Higher Education.” In The Palgrave Handbook of Critical Thinking in Higher Education, edited by Martin Davies and Ronald Barnett, 49-62. New York: Palgrave Macmillan

Baker, Vicki L., and Lisa R. Lattuca. 2010. "Developmental networks and learning: toward an interdisciplinary perspective on identity development during doctoral study." Studies in Higher Education 35 (7):807-27. doi: $10.1080 / 03075070903501887$.

Barron, Deirdre, and Margaret Zeegers. 2006. "Subjects of Western education: Discursive practices in Western postgraduate studies and the construction of international student subjectivities." The Australian Educational Researcher 33 (2):77-96. doi: 10.1007/bf03216835. 
Bøgelund, Pia. 2013. Enhancing the skills of PhD supervisors facing internationalization. Paper presented at the 41st SEFI Conference, Leuven, Belgium, 16-20 September 2013.

Bøgelund, Pia. 2015. "How supervisors perceive PhD supervision-And how they practice it." International Journal of Doctoral Studies 10:39-55.

Bøgelund, Pia, and Erik de Graaff. 2015. "The road to become a legitimate scholar: A case study of international PhD students in science and engineering." International Journal of Doctoral Studies 10 (unknown):519-33.

Brodin, Eva M. 2014. "Critical and creative thinking nexus: learning experiences of doctoral students." Studies in Higher Education:1-19. doi: 10.1080/03075079.2014.943656.

Bronfenbrenner, Urie. 2005. Making Human Being Human: Biological Perspectives on Human Development. Thousand Oaks, CA: Sage.

Carroll, Jude. 2015. Tools for teaching in an educationally mobile world. Abingdon, Oxon: Routledge.

Choy, Sarojni., Minglin Li., and Parlo Singh. 2015. "The Australian doctorate curriculum: responding to the needs of Asian candidates." International Journal for Researcher Development, 6 (2):165-182.

Church, Sarah Elizabeth. 2009. "Facing reality: What are doctoral students' chances for success?" Journal of Instructional Psychology 36 (4):307-16.

Davies, Martin, and Ronald Barnett, eds. 2015. The Palgrave Handbook of Critical Thinking in Higher Education. New York: Palgrave Macmillan.

Dolin, Jens. 2016. "Concerns with Using Test Results for Political and Pedagogical Purposes: A Danish Perspective." In Assessment in Education, Implications 
for leadership, edited by Shelleyann Scott, Donald E. Scott and Carles F. Webber, 91-112. London: Springer.

Dysthe, Olga. 2002. "Professors as Mediators of Academic Text Cultures." Written Communication, 19 (4): 493-544.

Egege, Sandra, and Salah Kutieleh. 2004. "Critical Thinking: Teaching Foreign Notions to Foreign Students." International Education Journal 4 (4):75-85.

Ekelund, Bjørn Z. 2010. "Cultural Perspectives on Team Consultation in Scandinavia: Experiences and Reflections." Scandinavian Journal of Organizational Psychology 2 (1).

Elliot, Dely Lazarte, Vivienne Baumfield, and Kate Reid. 2016. "Searching for 'a third space': a creative pathway towards international $\mathrm{PhD}$ students' academic acculturation." Higher Education Research \& Development 35 (6):1180-95. doi: 10.1080/07294360.2016.1144575.

Elliot, Dely Lazarte, Vivienne Baumfield, Kate Reid, and Kara A. Makara. 2016. "Hidden treasure: successful international doctoral students who found and harnessed the hidden curriculum." Oxford Review of Education 42 (6):73348. doi: 10.1080/03054985.2016.1229664.

Elliot, Dely Lazarte, Kate Reid, and Vivienne Baumfield. 2016. "Beyond the amusement, puzzlement and challenges: an enquiry into international students' academic acculturation." Studies in Higher Education 41 (12):2198-2217. doi: 10.1080/03075079.2015.1029903.

Fotovatian, Sepideh. 2012. "Three constructs of institutional identity among international doctoral students in Australia." Teaching in Higher Education, 17 (5): 577-588. 
Gardner, Susan K. 2007. "“I heard it through the grapevine": Doctoral student socialization in chemistry and history." Higher education 54 (5):723-40.

Hofstede, Geert. 1984. Culture's consequences: International differences in workrelated values. CA: Sage Publications.

Holbrook, Allyson, Kylie Shaw, Jill Scevak, Sid Bourke, Robert Cantwell, and Janene Budd. 2014. "PhD candidate expectations: Exploring mismatch with experience." International Journal of Doctoral Studies 9:329-46.

Hopmann, Stefan. 2007. "Restrained teaching: The common core of Didaktik." European Educational Research Journal 6 (2):109-24.

Hopmann, Stefan, and Kurt Riquarts. 2000. "Starting a dialogue: a beginning conversation between Didaktik and the curriculm traditions." In Teaching as a reflective practice: The German Didaktik tradition, 3-11. London: Lawrence Erlbaum Associates, Publishers.

Ives, Glenice, and Glenn Rowley. 2005. "Supervisor selection or allocation and continuity of supervision: PhD students' progress and outcomes." Studies in Higher Education 30 (5):535 - 55.

Jin, Lixian, and Martin Cortazzi. 2006. "Changing Practices in Chinese Cultures of Learning." Language, Culture and Curriculum 19 (1):5-20. doi: $10.1080 / 07908310608668751$.

Jindal-Snape, Divya, and Bart Rienties. 2016. Multi-dimensional transitions of international students to higher education. Oxon: Routledge.

Kidman, Joanna, Catherine Manathunga, and Sue Cornforth. 2017. "Intercultural $\mathrm{PhD}$ supervision: exploring the hidden curriculum in a social science faculty 
doctoral programme." Higher Education Research \& Development 36 (6):1208-21. doi: 10.1080/07294360.2017.1303457.

Kiley, Margaret. 1998. "'Expectation’in a cross cultural postgraduate experience." Quality in Postgraduate Research: Managing the new agenda Conference. The University of Adelaide, Adelaide.

Kiley, Margaret. 2003. "Conserver, Strategist or Transformer: The experiences of postgraduate student sojourners." Teaching in Higher Education, 8 (3): 345356. doi: 10.1080/13562510309401.

Kobayashi, Sofie. 2014. "Learning dynamics in doctoral supervision." PhD Diss., University of Copenhagen.

Kolmos, A., L. B. Kofoed, and X. Y. Du. 2008. "PhD students' work conditions and study environment in university- and industry-based PhD programmes." European Journal of Engineering Education 33 (5-6):539-50. doi: 10.1080/03043790802588383.

Lee, Boram, Susan P. Farruggia, and Gavin T. L. Brown. 2013. "Academic difficulties encountered by East Asian international university students in New Zealand." Higher Education Research \& Development 32 (6):915-31. doi: 10.1080/07294360.2013.806444.

Li, Jin. 2005. "Mind or Virtue. Western and Chinese Beliefs About Learning." Current Directions in Psychological Science 14 (4):190-4.

Lovitts, Barbara E. 2005. "Being a good course-taker is not enough: a theoretical perspective on the transition to independent research." Studies in Higher Education 30 (2):137-54. doi: 10.1080/03075070500043093. 
Maksimovic, Tijana, and Sofie Kobayashi. 2018. "Experiences of International PhD Students in Denmark as Quest Stories." Danish Journal of Teaching and Learning in Higher Education 13 (24):69-81.

Manalo, Emmanuel, Takashi Kusumi, Masuo Koyasu, Yashushi Michita, and Yuko Tanaka. (2015). "Do students fro different cultures think differently about critical and other thinking skills?" In The Palgrave Handbook of Critical Thinking in Higher Education, edited by Martin Davies and Ronald Barnett, 299-316. New York: Palgrave Macmillan.

Manathunga, Catherine, and Justine Goozée. 2007. "Challenging the dual assumption of the 'always/already' autonomous student and effective supervisor." Teaching in Higher Education 12 (3):309-22. doi: $10.1080 / 13562510701278658$.

McCormack, C. 2005. "Is non-completion a failure or a new beginning? Research non-completion from a student's perspective." Higher Education Research \& Development 24 (3):233-47.

Midgley, Carol, Avi Kaplan, and Michael Middleton. 2001. "Performance-approach goals: Good for what, for whom, under what circumstances, and at what cost?" Journal of Educational Psychology 93 (1):77-86. doi: 10.1037/00220663.93.1.77.

PhD-School. 2016. PhD School Annual Report 2016. Copenhagen, Denmark: University of Copenhagen, Faculty of Science.

Pyhältö, Kirsi, Auli Toom, Jenni Stubb, and Kirsti Lonka. 2012. "Challenges of becoming a scholar: A study of doctoral students' problems and well-being." International Scholarly Research Network ISRN Education 2012:1-12. 
Robinson-Pant, Anna. 2009. "Changing academies: exploring international PhD students' perspectives on 'host' and 'home' universities." Higher Education Research \& Development 28 (4):417-29. doi: 10.1080/07294360903046876.

Sakurai, Yusuke, Kirsi Pyhältö, and Sari Lindblom-Ylänne. 2012. "Factors affecting international doctoral students' academic engagement, satisfaction with their studies, and dropping out." International Journal for Researcher Development 3 (2):99-117. doi: doi:10.1108/17597511311316964.

Seagram, B.C., J. Gould, and S.W. Pyke. 1998. "An investigation of gender and other variables on time to completion of doctoral degrees." Research in higher education 39 (3):319-35.

Signorini, Paola, Rolf Wiesemes, and Roger Murphy. 2009. "Developing alternative frameworks for exploring intercultural learning: a critique of Hofstede's cultural difference model." Teaching in Higher Education 14 (3):253-64. doi: 10.1080/13562510902898825.

Smith, Jonathan A., and Mike Osborne. 2008. Interpretative Phenomenological Analysis in Smith, JA (Ed.) Qualitative psychology: A practical guide to research methods. (pp. 53-79). London: Sage Publications.

Tran, Ly Thi, Wendy Green, \& Lily Nguyen. 2017. Enhancing the Experience \& Outcomes of International Higher Degree Research Candidates: A Guide for Supervisors. Melbourne: International Education Association of Australia.

Virtanen, V., J. Taina, and K. Pyhältö. 2017. "What disengages doctoral students in the biological and environmental sciences from their doctoral studies?" Studies in Continuing Education 39 (1):71-86. doi: 10.1080/0158037X.2016.1250737. 
Winchester-Seeto, Theresa, Judi Homewood, Jane Thogersen, Christa JacenyikTrawoger, Catherine Manathunga, Anna Reid, and Allyson Holbrook. 2014. "Doctoral supervision in a cross-cultural context: issues affecting supervisors and candidates." Higher Education Research \& Development 33 (3):610-26.

Wisker, Gina. 2005. The good supervisor: Palgrave Macmillan.

Woolderink, Marla, Katarina Putnik, Hannerieke van der Boom, and Gonnie Klabbers. 2015. "The voice of $\mathrm{PhD}$ candidates and $\mathrm{PhD}$ supervisors. A qualitative exploratory study amongst $\mathrm{PhD}$ candidates and supervisors to evaluate the relational aspects of PhD supervision in the Netherlands." International Journal of Doctoral Studies 10 (unknown):217-35.

Xu, Linlin, and Barbara Grant. 2017. "International doctoral students' becoming: A dialogic perspective." Innovations in Education and Teaching International:1-10. doi: 10.1080/14703297.2017.1318711.

Yardley, Lucy. 2008. 'Demonstrating Validity in Qualitative Psychology.' In Qualitative psychology: A practical guide to research methods, edited by Jonathan Smith, 235-251. London: Sage Publications. 
Table

Table 1. Participants' profile

\begin{tabular}{|c|c|c|c|c|c|}
\hline \multicolumn{2}{|c|}{} & \multicolumn{2}{c|}{ Supervisors of international PhD students } \\
\hline International PhD students & Gender & $\begin{array}{l}\text { Country of } \\
\text { origin }\end{array}$ & Pseudonym & Gender & $\begin{array}{l}\text { Country } \\
\text { of origin }\end{array}$ \\
\hline Pseudonym & Female & Japan & Asger & Male & Denmark \\
\hline Susheila & Female & Bangladesh & Henning & Male & Denmark \\
\hline Devy & Female & India & Janne & Female & Denmark \\
\hline Wang & Male & China & Jeppe & Male & Denmark \\
\hline Reza & Male & Iran & Viola & Female & Denmark \\
\hline John & Male & Kenya & Anton & Male & Denmark \\
\hline
\end{tabular}

*None of the international PhD students and supervisors is in a paired supervisory relationship. 
Figures

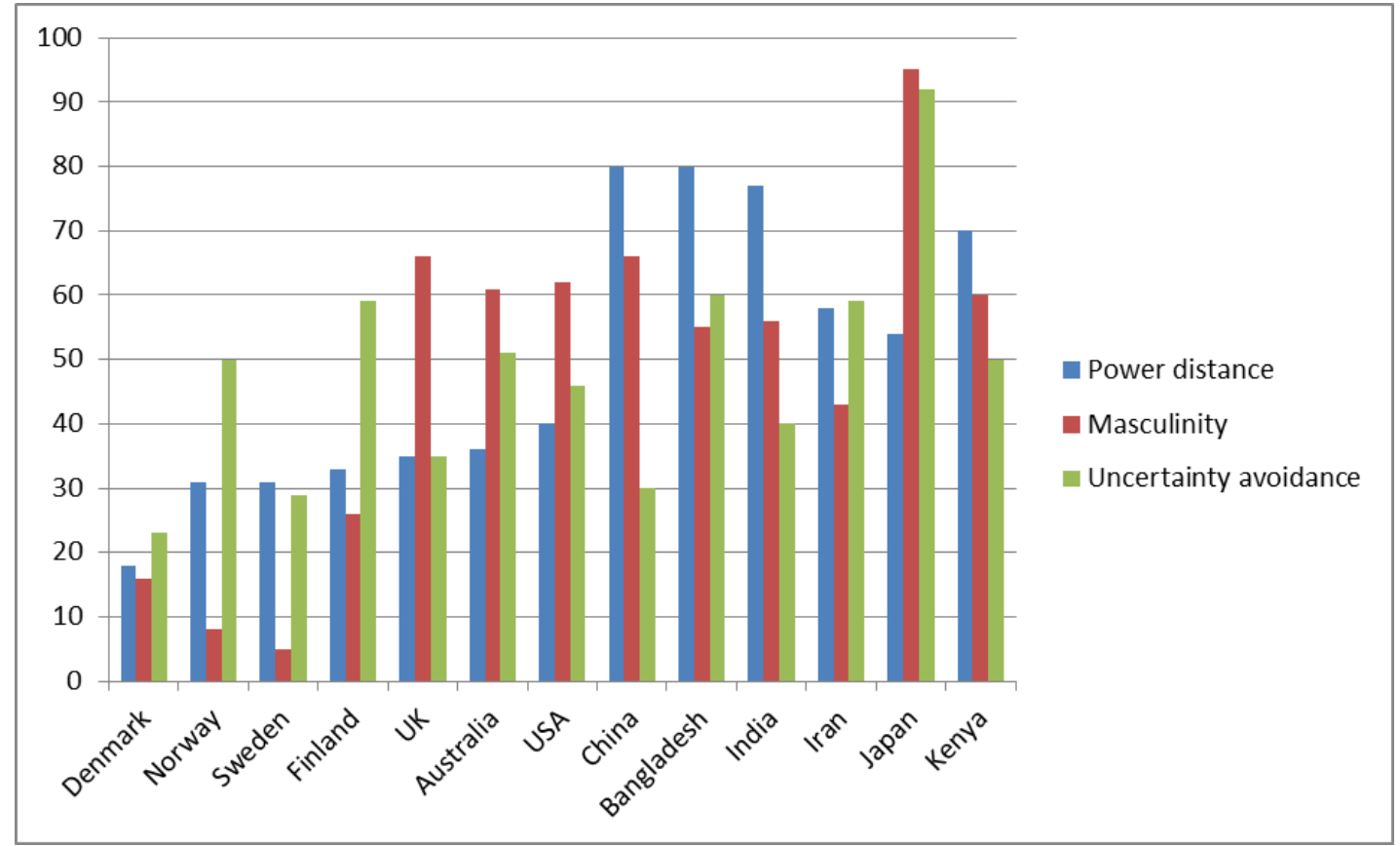

Figure 1. Denmark compared with Nordic countries (except Iceland), selected Anglo-American countries, and countries of $\mathrm{PhD}$ respondents in the study with regard to Hofstede's dimensions Power distance, Masculinity and Uncertainty avoidance. Values generated from https://geerthofstede.com/countries.html. 


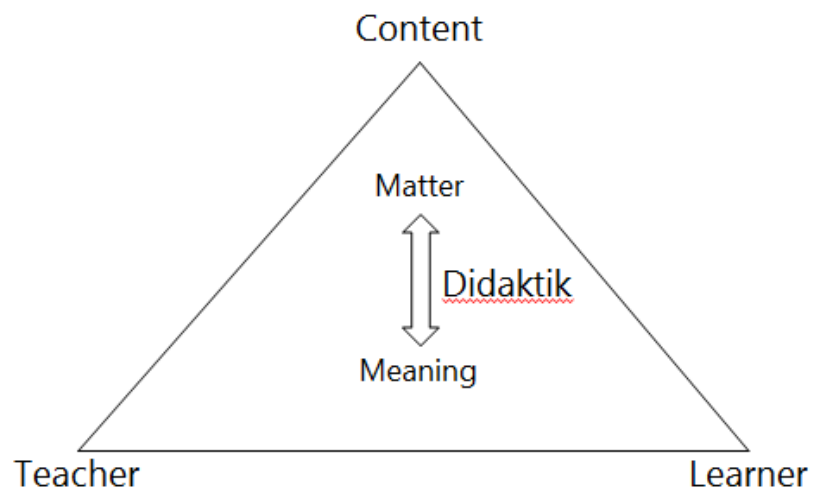

Figure 2. The Didaktik triangle (Hopmann 2007). 


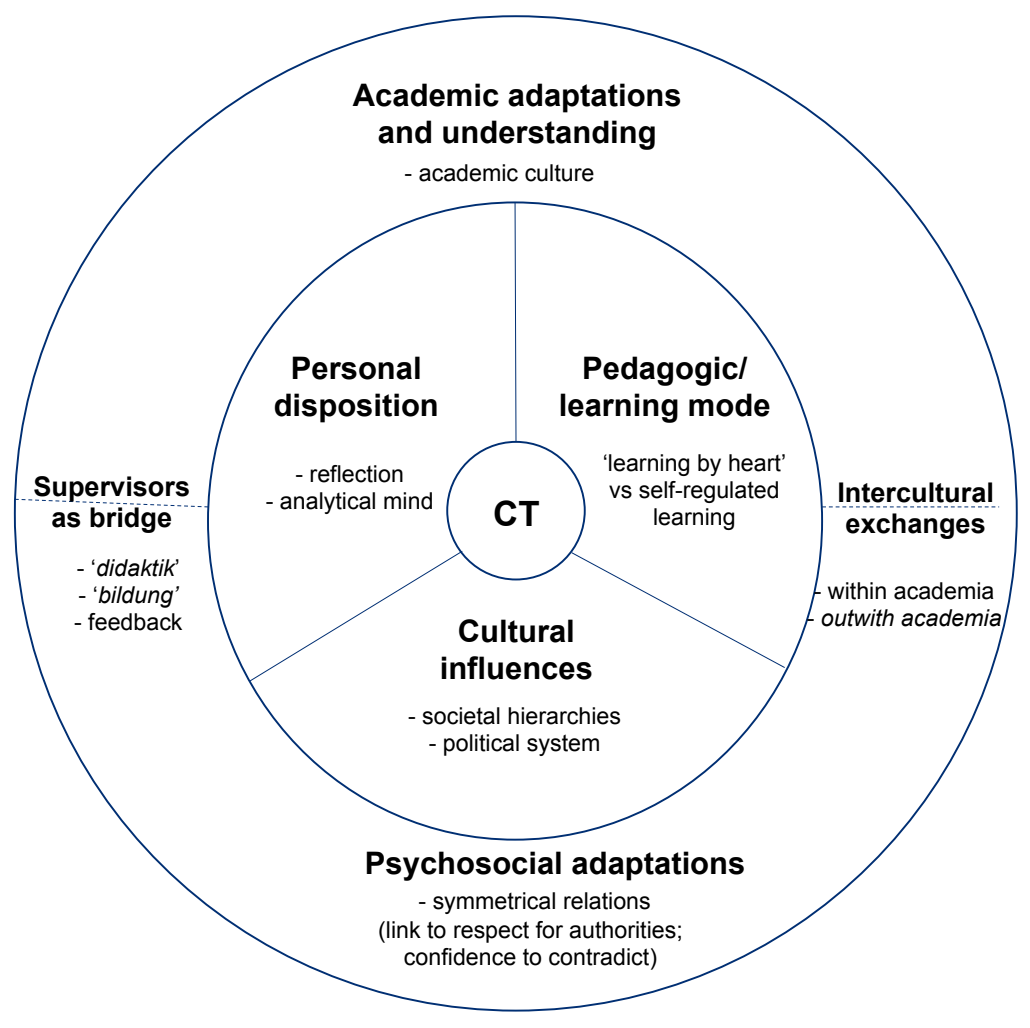

Figure 3. Critical thinking - a starting point for academic and psychosocial adaptations 